\title{
Evaluation of the Association of Public Reporting of Patient Ratings of US Primary Care Providers with Inappropriate Care
}

\author{
Norifumi Kamo, MD, MPP, Barbara L. Williams, PhD, and C. Craig Blackmore, MD, MPH \\ Center for Health Care Improvement Science, Virginia Mason Medical Center, Seattle, WA, USA.
}

J Gen Intern Med 34(3):336-7

DOI: $10.1007 / \mathrm{s} 11606-018-4706-1$

(c) Society of General Internal Medicine 2018

\section{INTRODUCTION}

Public sharing of patient experience scores to advance patient centeredness has gained traction but remains controversial due to concerns that this may inadvertently contribute to inappropriate care. ${ }^{1,2}$ Starting in October 2015, at Virginia Mason Medical Center, provider-level patient satisfaction ratings and comments were displayed prominently on the institutional public website. The objectives of this study were to determine whether measures of potentially inappropriate care changed following public sharing of patient satisfaction data, and secondarily to examine the relationship between inappropriate care and provider ratings.

\section{METHODS}

We performed a single-center retrospective cohort study from January 2015 to December 2017 of primary care providers who had at least 500 adult patient visits and 20 adult patient surveys both before and after the October 2015 initiation of public reporting. The intervention was public reporting of patient ratings of providers based on the 5-point Likert scale question "likelihood of your recommending care provider" (Clinician and Group Consumer Assessment of Healthcare Providers and Systems, Press Ganey Associates, South Bend, Indiana). Because higher patient satisfaction is associated with provider continuity, ${ }^{3}$ surveys were excluded if patients reported they were not visiting with their usual provider. For each provider, we also determined the rates of three a priori markers of potentially inappropriate care from the institutional electronic health record: antibiotics for acute respiratory illness (ARI) ${ }^{4}$ MRI for uncomplicated low back pain (using previously reported sets of ICD9/10 visit codes), ${ }^{5}$ and narcotic prescribing (any central nervous system depressant drug with abuse potential, including opiates, benzodiazepines, and barbiturates) for non-cancer patients. ${ }^{6}$

For the primary analysis of inappropriate care markers before and after the intervention, we conducted multilevel logistic regression models on patient visit-level data, clustering for provider. In separate models, the dependent variables were antibiotic order, lumbar MRI order, and narcotic order. Odds ratios

Published online October 18, 2018 were estimated adjusting for potential patient confounders (sex, age, new patient visit) and provider confounders (age, specialty, sex). Additional provider potential confounders considered but not included in the final model due to collinearity or lack of association with the outcomes were professional degree, years in practice, and years at our institution. Patient-level covariates considered but not included were race/ethnicity, education, self-rated health, and survey response method. Analysis of patient ratings of providers versus inappropriate care markers was performed using linear regression on provider-level data with adjustment for provider age. All analysis was performed using STATA MP 12 (Stata Corp, College Station, TX). This work was determined by the institutional review board to be quality improvement and exempt from formal review.

\section{RESULTS}

The study included 475,154 patient primary care visits, with 10,888 completed patient surveys for 74 providers (Table 1). The mean provider age was 47 years, with 19 years since medical school graduation, and 13 years at our institution. Most $(96 \%)$ were Medical Doctors and practiced Internal Medicine (80\%). During the study time frame, use of online rather than paper surveys increased (online 11\% (311/2960) to $66 \%,(5232 / 7928), p<0.001)$.

Public sharing of provider ratings was not associated with statistically significant increases in lumbar imaging rate (odds ratio (OR) $0.90,95 \%$ CI $0.62,1.30)$, antibiotic rate (OR 1.02, $95 \%$ CI $0.95,1.10)$, or narcotic rate (OR 1.01, 95\% CI 1.00 , 1.03) (Table 2).

After adjustment for provider age, the potentially inappropriate care markers of lumbar imaging (attributable risk (AR) $-0.014,95 \%$ CI $-0.321,0.293$ ), antibiotics for ARI (AR $0.096,95 \% \mathrm{CI}-0.318,0.127$ ), and narcotic order (AR 0.545, $95 \%$ CI $-0.021,1.112$ ) were not associated with higher provider ratings. The mean provider rating both before and after public reporting was $4.81(p=0.66)$.

\section{DISCUSSION}

Public reporting of provider ratings was not associated with increase in the inappropriate care markers of antibiotics for ARI, imaging for low back pain, or prescribing narcotics. Further, there was no significant association between patient 
Table 1 Patient Surveys and Patient Primary Care Visits Before and After Public Reporting of Quality Ratings

\begin{tabular}{|c|c|c|c|}
\hline & $\begin{array}{l}\text { Prior to public reporting } \\
\text { (Jan 2015-Oct 2015) }\end{array}$ & $\begin{array}{l}\text { After public reporting } \\
\text { (Nov 2015-Dec 2017) }\end{array}$ & Sig $p$ \\
\hline \multicolumn{4}{|l|}{ Primary care clinic visits } \\
\hline All non-cancer visits, number & 150,356 & 324,798 & \\
\hline Patient age, mean (SD) & $56.1(17.8)$ & $56.2(17.4)$ & 0.020 \\
\hline Female patient $(\%)$ & $87,532(58)$ & $184,000(57)$ & $<0.001$ \\
\hline New patient $(\%)$ & $7558(5.0)$ & $14,328(4.4)$ & $<0.001$ \\
\hline Back pain index visits, number & 1438 & 2145 & \\
\hline \multirow[t]{2}{*}{ URI index visits, number } & 8074 & 16,015 & \\
\hline & $\begin{array}{l}\text { Prior to public reporting } \\
\text { (Jan 2015-Oct 2015) }\end{array}$ & $\begin{array}{l}\text { After public reporting } \\
\text { (Nov 2015-Apr 2016) }\end{array}$ & $\operatorname{Sig} p$ \\
\hline \multicolumn{4}{|l|}{ Complete patient surveys } \\
\hline Number & 2960 & 7928 & \\
\hline Device type & & & $<0.001$ \\
\hline Online computer & $311(11 \%)$ & $5232(66 \%)$ & \\
\hline Mobile phone & $45(1 \%)$ & $853(11 \%)$ & \\
\hline Mobile tablet & $33(1 \%)$ & $515(7 \%)$ & \\
\hline Mail & $2571(87 \%)$ & $1328(17 \%)$ & \\
\hline Patient mean age (SD) & $64.0(14.6)$ & $59.0(14.4)$ & $<0.001$ \\
\hline Patient, female $(\%)$ & $1747(59 \%)$ & $4422(56 \%)$ & 0.002 \\
\hline Patient, non-Hispanic White & $2483 / 2919(85 \%)$ & $6495 / 6902(94 \%)$ & $<0.001$ \\
\hline Patient, college grad (\%) & $1789 / 2875(62 \%)$ & $5251 / 7850(67 \%)$ & $<0.001$ \\
\hline Patient, self-rated health excellent (\%) & $538(18 \%)$ & $1513(19 \%)$ & 0.28 \\
\hline
\end{tabular}

Table 2 Association Between Potentially Inappropriate Care Markers and Public Reporting of Quality Ratings, by Visit

\begin{tabular}{|c|c|c|c|c|c|c|c|c|}
\hline & \multirow[b]{2}{*}{$N$} & \multicolumn{4}{|l|}{ Unadjusted } & \multicolumn{3}{|l|}{ Adjusted* } \\
\hline & & $\begin{array}{l}\text { Orders per visit } \\
\text { pre-intervention, } \\
\text { mean (SD) }\end{array}$ & $\begin{array}{l}\text { Orders per visit } \\
\text { post-intervention, } \\
\text { mean (SD) }\end{array}$ & $\begin{array}{l}95 \% \text { CI of } \\
\text { difference }\end{array}$ & $\operatorname{Sig} p$ & $\begin{array}{l}\text { Odds ratio } \\
\text { (after versus before } \\
\text { public reporting) }\end{array}$ & $95 \% \mathrm{CI}$ & $\operatorname{Sig} p$ \\
\hline Lumbar imaging & 3583 & $0.120(0.325)$ & $0.111(0.314)$ & $-0.012,0.031$ & 0.39 & 0.90 & $0.62,1.30$ & 0.57 \\
\hline ARI antibiotic & 24,089 & $0.192(0.394)$ & $0.202(0.401)$ & $-0.020,0.001$ & 0.07 & 1.02 & $0.95,1.10$ & 0.55 \\
\hline Narcotic & 475,154 & $0.141(0.348)$ & $0.144(0.351)$ & $-0.005,-0.001$ & 0.015 & 1.01 & $1.00,1.03$ & 0.11 \\
\hline
\end{tabular}

*From multilevel logistic model clustering by provider $(N=74)$ and adjusting for provider age, specialty and gender, and patient age and gender; narcotic orders also adjusting for new patient $(Y / N)$

provider rating and these markers of potentially inappropriate care at baseline.

This study reflects the experience at a single institution only. Limitations include a potential ceiling effect, survey response bias, residual confounding from changing patient and survey characteristics, and changes in scores with time independent of public sharing of survey results.

We conclude that concerns that public reporting of provider rating scores may drive providers toward inappropriate overutilization may be unwarranted.

Corresponding Author: C. Craig Blackmore, MD, MPH; Center for Health Care Improvement Science Virginia Mason Medical Center, Seattle, WA, USA (e-mail: craig.blackmore@virginiamason.org).

\section{Compliance with Ethical Standards:}

Conflicts of Interest: The authors declare that they do not have a conflict of interest.

\section{REFERENCES}

1. Fenton JJ, Jerant AF, Bertakis KD, Franks P. The Cost of Satisfaction: A National Study of Patient Satisfaction, Health Care Utilization, Expenditures, and Mortality. Arch Intern Med 2012;172(5):405-411. https://doi. org/10.1001/archinternmed.2011.1662

2. Zgierska A, Miller M, Rabago D. Patient Satisfaction, Prescription Drug Abuse, and Potential Unintended Consequences. JAMA 2012;307(13):1377-1378. https://doi.org/10.1001/jama.2012.419.

3. Fan VS, Burman M, McDonell MB, Fihn SD. Continuity of Care and Other Determinants of Patient Satisfaction with Primary Care. J Gen Intern Med 2005;20(3):226-233. https://doi.org/10.1111/j.1525-1497. 2005.40135.x.

4. Pittenger, Kim, et al. Improving acute respiratory infection care through nurse phone care and academic detailing of physicians. J Am Board Fam Med 28.2 (2015): 195-204.

5. National Committee for Quality Assurance (NCQA). HEDIS 2016: Healthcare Effectiveness Data and Information Set. Vol. 1, narrative. Washington (DC): National Committee for Quality Assurance (NCQA); 2015. various $\mathrm{p}$.

6. U.S. Department of Health and Human Services (HHS), Office of the Surgeon General, Facing Addiction in America: The Surgeon General's Report on Alcohol, Drugs, and Health. Washington, DC: HHS, November 2016. 